\title{
Variation amongst human isolates of Brachyspira (Serpulina) pilosicoli based on biochemical characterization and 165 rRNA gene sequencing
}

\author{
Koen A. L. De Smet, † Debbie E. Worth and Stephen P. Barrett \\ Author for correspondence: Koen A. L. De Smet. Tel: + 3292410711 . Fax: 3292410799. \\ e-mail: Koenraad_De_Smet $\alpha$ innogenetics.be
}

Department of Infectious Diseases and Microbiology, Imperial College School of Medicine at St Mary's, Norfolk Place, London W2 1PG, UK

\begin{abstract}
Brachyspira pilosicoli (formerly Serpulina pilosicoli) causes swine spirochaetosis and can also be isolated from human faeces, although its role in human disease remains unclear. The genetic and biochemical variations amongst 19 isolates of human spirochaetes from five different countries were evaluated and compared to those found amongst swine isolates of $B$. pilosicoli. All isolates were negative for $\beta$-glucosidase and all but one were positive for hippurate hydrolysis, which are characteristics typical of $B$. pilosicoli. The isolates showed variation in indole production and $\alpha$ galactosidase and $\alpha$-glucosidase activity, other characteristics which can be used to identify B. pilosicoli. The DNA sequences of part of the 16S rRNA gene differed from each other and from that of B. pilosicoli by 0-3 bp out of $283 \mathrm{bp}$. It is concluded that there is considerable variation amongst human intestinal spirochaetes. Since few of the isolates reported here match the current criteria for B. pilosicoli, it is concluded that this species is more heterogeneous than previously appreciated. However, it cannot be excluded that some isolates may belong to uncharacterized related BrachyspiralSerpulina species.
\end{abstract}

Keywords: human intestinal spirochaete, Brachyspira pilosicoli, 16S rRNA analysis

\section{INTRODUCTION}

Although both man and animals have been known to harbour intestinal spirochaetes for over a century, their taxonomic divisions and pathological significance have only recently been addressed. At present, there is evidence that there are at least two species of human intestinal spirochaetes: Brachyspira pilosicoli (formerly Serpulina pilosicoli; Validation List No. 64, 1998) and the rarely reported and human-specific Brachyspira aalborgi (Trott et al., 1996c; HovindHougen et al., 1982).

Isolates of Brachyspira/Serpulina obtained from swine faeces have received more attention in the last few

†Present address: Innogenetics NV, Departement Microbiologie, Industriepark 7, Bus 4, B-9052 Zwijnaarde (Gent), Belgium.

Abbreviation: MEE, multilocus enzyme electrophoresis.

The EMBL/GenBank/DDBJ accession numbers for the sequences reported in this paper are Y10314-Y10317. years, and the number of species in this genus has been extended from two to five (Trott et al., 1996a; Stanton et al., 1997). Brachyspira hyodysenteriae (formerly Serpulina hyodysenteriae; Validation List No. 64, 1998 ) is the cause of swine dysentery (Taylor \& Alexander, 1971). Brachyspira innocens (formerly Serpulina innocens; Validation List No. 64, 1998) is closely related, but not pathogenic. The recently described $B$. pilosicoli can cause intestinal spirochaetosis in pigs (Trott et al., 1996b; Muniappa et al., 1997; Thomson et al., 1997). The pathogenic potential of the recently described Serpulina intermedia and Serpulina murdochii remains largely unknown. A simple biochemical classification has recently been described for swine isolates, dividing Brachyspira/Serpulina in six groups that represent the five species mentioned and a sixth, unnamed group (Fellström \& Gunnarson, 1995; Stanton et al., 1997).

The phylogeny of human intestinal spirochaetes has been studied using multilocus enzyme electrophoresis (MEE) (Lee \& Hampson, 1994), PAGE (Barrett et al., 
1996) and PFGE (Atyeo et al., 1996; Rayment et al., 1997). These techniques revealed considerable heterogeneity amongst human isolates, but the isolates fell into a distinct group (Lee \& Hampson, 1994; Barrett et al., 1996). This heterogeneous group also contained isolates from swine and other animals, including strain $\mathrm{P} 43 / 6 / 78^{\mathrm{T}}$, the type strain of $B$. pilosicoli (Stanton et al., 1996; Lee \& Hampson, 1994). Although these techniques are useful for epidemiology, they cannot be used to assign species status to the human intestinal spirochaetes. Further evidence that human intestinal spirochaetes are $B$. pilosicoli comes from immunoblotting with a species-specific monoclonal antibody (Rayment et al., 1997), species-specific PCR (Park et al., 1995; Trott et al., 1997) and partial 16S rDNA sequencing of two isolates (Stanton et al., 1996). Biochemical analysis of three human intestinal spirochaetes and seven spirochaetes isolated from human blood identified them as B. pilosicoli and it has been suggested that blood isolates may have originated in the intestinal tract (Trott et al., 1996c, 1997).

This study was initiated to further compare human intestinal spirochaetes to swine isolates of $B$. pilosicoli and to assess the genetic and biochemical variability of human isolates of $B$. pilosicoli from five different countries.

\section{METHODS}

Isolates and culture. The isolates of spirochaetes from faecal cultures of patients in Australia, Britain, Italy and Oman, and from blood cultures of patients in France have been described previously (Table 1) (Lee \& Hampson, 1992; Barrett, 1990; Sanna et al., 1982; Trott et al., 1997). They were stored at $-70^{\circ} \mathrm{C}$ in $10 \%(\mathrm{w} / \mathrm{v})$ glycerol broth and cultured anaerobically at $37^{\circ} \mathrm{C}$ on Columbia agar base with $5 \%(\mathrm{v} / \mathrm{v})$ sheep blood. Subculture onto fresh agar was performed after $7 \mathrm{~d}$ and the organisms were harvested after a further $2 \mathrm{~d}$ incubation.

Phenotypic characterization. Hippurate hydrolysis and indole production were performed as described previously (Fellström \& Gunnarson, 1995). $\beta$-Haemolysis was assessed on the plates used for culture. $\alpha$-Galactosidase, $\alpha$-glucosidase and $\beta$-glucosidase were tested and scored using the API-ZYM kit according to manufacturer's instructions (Marcy-l'Etoile). All assays were compared with results obtained using $B$. hyodysenteriae $\mathrm{B} 78^{\mathrm{T}}$ and $B$. innocens $\mathrm{B} 256^{\mathrm{T}}$ as reference strains.

Lysis of bacteria and PCR. A loopful of bacteria was suspended in $500 \mu 10 \mathrm{mM}$ Tris $/ \mathrm{HCl}$ buffer $\mathrm{pH} 8.0$ plus $0.1 \mathrm{mM}$ EDTA. The bacteria were collected by centrifugation and the supernatant was discarded. Chloroform $(100 \mu \mathrm{l})$ was added and the bacteria were resuspended by vigorous vortexing. An equal volume of water was added and the suspension was mixed. After centrifugation to separate the phases, the aqueous phase was recovered and again extracted with chloroform. The resulting aqueous phase was used for PCR.

The primers 285 (sequence 5' GAGAGTTTGATCCTGGCTCAG $3^{\prime}$ ) and 244 (5' CCCACTGCTGCCTCCCGTAG 3') (Kirschner et al., 1993; De Smet et al., 1995) amplify around $360 \mathrm{bp}$ of the $5^{\prime}$ end of the $16 \mathrm{~S}$ rRNA gene. DNA present in $1 \mu \mathrm{l}$ lysate was amplified in a total volume of $50 \mu \mathrm{l}$ containing $0.5 \mu \mathrm{M}$ of each primer, $200 \mu \mathrm{M}$ of each nucleotide, $5 \mu \mathrm{l} 10 \times$ buffer and $2.5 \mathrm{U}$ Taq polymerase, (Gibco/BRL) covered by one drop of mineral oil. The DNA was amplified with two cycles of $96^{\circ} \mathrm{C}$ for $2.5 \mathrm{~min}, 55^{\circ} \mathrm{C}$ for $30 \mathrm{~s}$ and $72^{\circ} \mathrm{C}$ for $1 \mathrm{~min}$, followed by 35 cycles of $95^{\circ} \mathrm{C}$ for $1 \mathrm{~min}, 55^{\circ} \mathrm{C}$ for $30 \mathrm{~s}$ and $72^{\circ} \mathrm{C}$ for $1 \mathrm{~min}$, and one cycle of $72{ }^{\circ} \mathrm{C}$ for $10 \mathrm{~min}$. Blank controls (samples without DNA) were included throughout.

DNA sequencing. The whole PCR sample was run on a $1.5 \%$ $(\mathrm{w} / \mathrm{v})$ agarose gel to remove primers, the appropriate band was cut out with a scalpel and purified using the QIAEX-II kit (Qiagen) according to the manufacturer's instructions. A quarter of the $20 \mu \mathrm{l}$ purified PCR product was used for dye terminator fluorescence sequencing by mixing with $1 \mu \mathrm{l}$ primer (either 285 or 244) and $4 \mu 1$ ABI PRISM Dye Terminator Cycle Sequencing Ready Reaction mix with AmpliTaq FS (PE Applied Biosystems), and covered with one drop of mineral oil. This was then cycled through 30 cycles of $95^{\circ} \mathrm{C}$ for $1 \mathrm{~min}, 55^{\circ} \mathrm{C}$ for $30 \mathrm{~s}$ and $72{ }^{\circ} \mathrm{C}$ for $1 \mathrm{~min}$. The sequencing product was diluted to $50 \mu \mathrm{l}$, precipitated, washed with $70 \%(\mathrm{v} / \mathrm{v})$ ethanol, dried and dissolved in $12 \cdot 5 \mu \mathrm{l}$ Template Suppression Reagent (PE Applied Biosystems). After heating at $95^{\circ} \mathrm{C}$ for $5 \mathrm{~min}$, the samples were loaded in an ABI PRISM 310 Genetic Analyzer (PE Applied Biosystems) and run according to the manufacturer's instructions.

DNA sequence analysis. All computer analyses were performed using the GCG Wisconsin Sequence Analysis Package, version 8.1.0 (Genetics Computer Group, WI, USA). Homologous sequences were identified by searching the GenBank or EMBL databases using the FASTA program. Retrieved sequences were aligned using PILEUP, which creates a multiple sequence alignment using progressive, pairwise alignments. Default values of the program were used. Pairwise homologies between the aligned sequences were calculated with the DISTANCES program using the uncorrected distances method, with a penalty of 1.0 for each gap and ignoring any ambiguities.

\section{RESULTS}

\section{Phenotypic characterization}

All 19 isolates were analysed for haemolysis, indole production, hippurate hydrolysis and $\alpha$-galactosidase, $\alpha$-glucosidase and $\beta$-glucosidase activities; results were compared with an existing scheme for classification of Brachyspira/Serpulina species (Fellström \& Gunnarson, 1995) (Table 1). All of the human intestinal spirochaetes were weakly haemolytic. All but one were positive for hippurate hydrolysis and all were negative for $\beta$-glucosidase activity, two characteristics reported to be unique to B. pilosicoli (Fellström \& Gunnarson, 1995). There was more variation in the results for the other assays, with over half the isolates differing in one to three characteristics from the proposed $B$. pilosicoli scheme. Over half the isolates had weak $\alpha$-galactosidase activity. None of the isolates fell into any of the other groups proposed for the other species in the genus (Fellström \& Gunnarson, 1995). All five countries provided isolates with aberrant biochemical characteristics. 
Table 1. Isolates and their characteristics

Biochemical and partial 16S rDNA sequence of the first 19 isolates were determined in this study. - , No activity; \pm , weak activity; and + , strong activity. The biochemical data or 16S rDNA sequence of the other isolates were obtained from published work or the GenBank or EMBL DNA databases. References refer to the description of the isolate for those used in this study, or the published biochemical characteristics for other isolates mentioned. Species assignation for published sequences is as described in the database entries or the corresponding paper. Haem, haemolysis; Ind, indole; Hip, hippurate; $\alpha$-Gal, $\alpha$-galactosidase; $\alpha$-Glc, $\alpha$-glucosidase; $\beta$-Glc, $\beta$-glucosidase.

\begin{tabular}{|c|c|c|c|c|c|c|c|c|c|c|c|c|}
\hline Isolate & Clinical symptoms/comments & Country & Haem & Ind & Hip & $\alpha$-Gal & $\alpha$-Glc & $\beta$-Gle & Sequence & Species & Accession no. & Reference \\
\hline 57 & & Oman & Weak & - & + & \pm & - & - & IS-A & & Y 10314 & Barrett et al. (1996) \\
\hline 91 & Old paralysis & Oman & Weak & + & + & \pm & - & - & IS-A & & & Barrett et al. (1996) \\
\hline 108 & None apparent & Oman & Weak & + & + & \pm & - & - & IS-A & & & Barrett et al. (1996) \\
\hline HRM-7 & Carcinoma of liver & Italy & Weak & - & + & - & - & - & IS-A & & & Sanna et al. (1982) \\
\hline $81-80$ & $\begin{array}{l}\text { Septicaemia, fever } 40.9^{\circ} \mathrm{C} \text {, stroke, } \\
\text { hemiplegia, death }\end{array}$ & France & Weak & - & + & + & + & - & IS-A & & & Trott et al. (1997) \\
\hline $28-94$ & Septicaemia & France & Weak & - & + & + & - & - & IS-A & & & Trott et at. (1997) \\
\hline $128-90$ & $\begin{array}{l}\text { Septicaemia, acute peritonitis, } \\
\text { necrosis of caecum, recovered }\end{array}$ & France & Weak & - & + & - & - & - & IS-A & & & Trott et al. (1997) \\
\hline Gel & Diarrhoea & UK & Weak & - & - & \pm & - & - & IS-A & & & Unpublished \\
\hline GOR & Diarhoea: HIV + & UK & Weak & - & + & \pm & - & - & IS-A & & & Unpublished \\
\hline Matthew & Diarrhoea & Australia & Weak & - & + & \pm & - & - & IS-A & & & Lee \& Hampson (1992) \\
\hline Karlos & Diarrhoea & Australia & Weak & + & + & \pm & - & - & IS-A & & & Lee \& Hampson (1992) \\
\hline 54 & Epigastric pain, vomiting, diarrhoea & Oman & Weak & - & + & \pm & -- & - & IS-B & & Y10315 & Barrett et al. (1996) \\
\hline 85 & Acute pain and vomiting & Oman & Weak & - & + & + & - & - & IS-C & & Y10316 & Barrett et al. (1996) \\
\hline 89 & Acute pain for one day & Oman & Weak & + & + & - & - & - & IS-D & & Y10317 & Barrett et al. (1996) \\
\hline HPR-1 & Diarrhoea, abdominal pain & Italy & Weak & - & + & - & - & - & IS-D & & & Sanna et al. (1982) \\
\hline $382-91$ & Septicaemia, alcoholic, myeloma & France & Weak & - & + & \pm & - & - & IS-D & & & Trott et al. (1997) \\
\hline FT-7 & & UK & Weak & - & + & \pm & - & - & IS-D & & & Unpublished \\
\hline Steptoe & Rectal bleeding; HIV + & UK & Weak & - & + & \pm & - & - & IS-D & & & Unpublished \\
\hline Jeremiah & Diarrhoea & Australia & Weak & + & + & - & + & - & IS-D & & & Lee \& Hampson (1992) \\
\hline N HRM7 & Carcinoma of liver & & & & & & & & & B. pilosicoli & Z26968; U23031 & \\
\hline N-Wes-B & & & & & & & & & & B. pilosicoli & Z26967; U23034 & \\
\hline $\mathrm{P} 43 / 6 / 78^{\mathrm{T}}$ & Type strain, diarrhoeic pig & Scotland & Weak & - & + & + & - & - & & B. pilosicoli & U14927; U23032 & Fellström \& Gunnarsson (1995) \\
\hline $\mathrm{B} 78^{\mathrm{T}}$ & Type strain & & Strong & + & - & - & + & + & & B. hyodysenteriae & U14930; M57743 & Fellström \& Gunnarsson (1995) \\
\hline $\mathrm{B} 256^{\mathrm{T}}$ & Type strain & & Weak & - & - & + & + & + & & B. innocens & U14920; M57744 & Fellström \& Gunnarsson (1995) \\
\hline $\mathrm{PWS} / \mathrm{A}^{\mathrm{T}}$ & Type strain, pig isolate & & Weak & + & - & - & + & + & & S. intermedia & U23033 & Trott et al. $(1996 c)$ \\
\hline $56-150^{\mathrm{T}}$ & Type strain & & Weak & - & - & - & - & + & & S. murdochii & & Stanton et al. (1997) \\
\hline $155-20$ & & & & & & & & & & S. murdochii & U22838 & Stanton et al. (1997) \\
\hline NCTC $11492^{\mathrm{T}}$ & Type strain & & & & & & & & & B. aalborgi & Z22781 & \\
\hline
\end{tabular}

Table 2. Difference matrix for the $16 \mathrm{~S}$ rRNA gene of selected Brachyspira/Serpulina sequences

The numbers to the right and above the diagonal represent the number of different nucleotides in the 283 bp region analysed in this study. The values to the left and underneath the diagonal represent the percentage difference for published $16 \mathrm{~S}$ rDNA sequences over a region of $1400 \mathrm{bp}$.

\begin{tabular}{|c|c|c|c|c|c|c|c|c|c|c|}
\hline & IS-A & B. pilosicoli & IS-B & IS-C & IS-D & B. innocens & B. hyodysenteriae & S. murdochii & S. intermedia & B. aalborghi \\
\hline IS-A & - & 0 & 1 & 2 & 1 & 12 & 10 & 15 & 12 & 22 \\
\hline B. pilosicoli & & - & 1 & 2 & 1 & 15 & 13 & 18 & 15 & 25 \\
\hline IS-B & & & - & 3 & 1 & 13 & 11 & 16 & 13 & 23 \\
\hline IS-C & & & & - & I & 12 & 10 & 15 & 12 & 22 \\
\hline IS-D & & & & & & 13 & 11 & 16 & 13 & 23 \\
\hline B. innocens & & $3.37 \%$ & & & & - & 2 & 7 & 8 & 14 \\
\hline B. hyodysenters, & & $4.61 \%$ & & & & $2.78 \%$ & - & 7 & 10 & 14 \\
\hline S. murdochii & & $3.07 \%$ & & & & $1.97 \%$ & $3.80 \%$ & - & 9 & 17 \\
\hline S. intermedia & & $2.34 \%$ & & & & $2.05 \%$ & $3.29 \%$ & $1.02 \%$ & - & 19 \\
\hline B. aalborghi & & $5.05 \%$ & & & & $4.32 \%$ & $5.64 \%$ & $4 \cdot 10 \%$ & $3.95 \%$ & - \\
\hline
\end{tabular}

\section{Partial sequencing of the 16S rRNA gene}

The $5^{\prime}$ end of the $16 \mathrm{~S}$ rRNA gene from 19 isolates of human intestinal spirochaetes was amplified using primers 285 and 244 (Kirschner et al., 1993; De Smet et al., 1995) to produce a PCR fragment of around $360 \mathrm{bp}$. This region contains $41 \%$ of all substitutions identified in the $16 \mathrm{~S}$ rRNA genes of around 30 intestinal spirochaete isolates (Fellström et al., 1995; Stanton et al., 1996; Petterson et al., 1996). These PCR products were sequenced on both strands, with the oligonucleotides used for amplification as the sequencing primers. A region of 283 bp was sequenced for all isolates. Sequence differences were confirmed by repeating the PCR and sequencing. This showed that the isolates were highly homologous, with $0-3 \mathrm{bp}$ differences amongst them (Table 2 ).

Overall, four distinct sequences were obtained, which, for convenience, are identified as IS-A, IS-B, IS-C and 

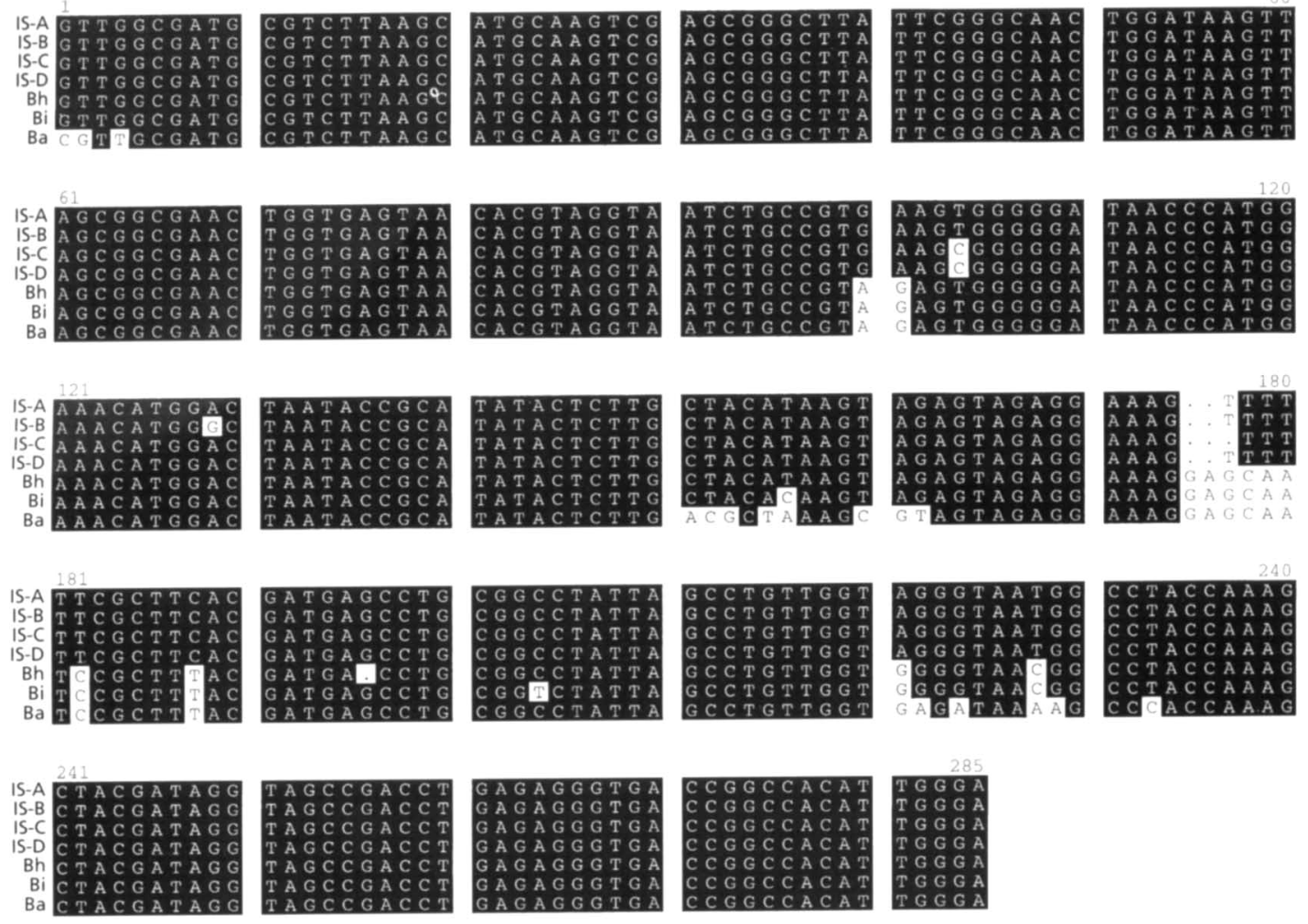

Fig. 1. Alignment of the IS-A, IS-B, IS-C and IS-D sequences with $16 \mathrm{~S}$ rRNA sequence of $B$. hyodysenteriae (Bh; accession number $\mathrm{U} 14930), B$. innocens ( $\mathrm{Bi}$; accession number $\mathrm{U} 14920$ ) and $B$. aalborghi ( $\mathrm{Ba}$; accession number $\mathrm{Z2278}$ ).

IS-D (IS, intestinal spirochaete) (Fig. 1). Isolates with sequence IS-A accounted for over half of all isolates (Table 1). Only one isolate was found with sequence IS-B and only one had IS-C. All countries provided isolates with sequences IS-A and IS-D. The single isolates with sequences IS-B and IS-C were both from Omani patients. Also, there was no correlation between DNA sequence and biochemical analysis. Samples with an aberrant result for the indole reaction, $\alpha$-galactosidase or $\alpha$-glucosidase had either an IS-A or IS-D sequence.

\section{Computer analysis of sequences}

The sequences obtained were submitted to the EMBL/GenBank/DDBJ databases (accession nos Y10314, Y10315, Y10316 and Y 10317). Sequence database searches using the FASTA program revealed that the IS sequences showed highest homology to those of other intestinal spirochaetes belonging to the Brachyspira/Serpulina genus.

A perfect match was found between IS-A and three independent swine Brachyspira/Serpulina isolates (accession nos U14927, U14928 and U14929) (Petterson et al., 1996). These three $16 \mathrm{~S}$ rRNA gene sequences differed outside the $283 \mathrm{bp}$ region analysed here. One of these isolates was the $B$. pilosicoli type strain $\mathrm{P} 43 / 6 / 78^{\mathrm{T}}$. The IS-A sequence was also identical to the partial 16S rRNA gene sequences of the human isolate HRM-7, deposited in the database by $\mathrm{J}$. V. Hookey and others (accession no. Z26968; unpublished data). However, it differed by $1 \mathrm{bp}$ from the sequence submitted by Stanton et al. (1996) for the same isolate (accession no. U23031). Sequencing of isolate HRM-7 showed that it was identical to the Hookey sequence and thus belongs to the IS-A type.

Similarly, the IS-D sequence was identical to the partial 16S DNA sequences of the human intestinal isolate $\mathrm{N}$ Wes-B, obtained by J. V. Hookey and others (accession no. Z26967; unpublished data), but differed by $3 \mathrm{bp}$ from the sequence of Stanton et al. (1996) for the same isolate (accession no. U23034). There were no perfect matches for the IS-B and IS-C sequences.

All IS sequences differed by at least $10 \mathrm{bp}$ from the other Brachyspira/Serpulina sequences, B. hyodysenteriae, B. innocens, $S$. murdochii and $S$. intermedia and other isolates not yet assigned to any formally recognized species (Fig. 1 and data not shown). All Brachyspira/Serpulina sequences differed from that of B. aalborgi by $14-25 \mathrm{bp}$.

\section{DISCUSSION}

Recent work has shown that isolates of human intestinal spirochaetes are heterogeneous, but closely related to or indistinguishable from B. pilosicoli (Lee \& 
Hampson. 1994; Trott et al., 1996c; Atyeo et al., 1996; Rayment et al., 1997). Since biochemical analysis and 16S rDNA sequencing were only performed on a few isolates (Stanton et al., 1996; Trott et al., 1997), a larger collection of human intestinal spirochaetes was characterized in this study to confirm their species status and determine intra-species variability.

The biochemical typing presented here shows that all but one of the human isolates were positive for hippurate hydrolysis and negative for $\beta$-glucosidase activity, two characteristics unique to $B$. pilosicoli. There was more variation in the other biochemical characteristics, supporting the heterogeneity found using MEE, PAGE and PFGE. The majority of isolates had only weak $\alpha$-galactosidase activity. It is not clear from published work if a weak or strong reaction is expected as only a positive or negative was indicated (Fellström \& Gunnarsson, 1995; Trott et al., $1996 \mathrm{c}, 1997)$. Biochemical variation was also found in analysis of the seven human bloodborne spirochaetes, four of which were re-analysed in this study (Trott et al., 1997). This variation is in contrast to results on swine isolates, where 165 Brachyspira/Serpulina isolates could be placed into six groups, representing the five species and an unnamed group IIIb, without any apparent variation in biochemical characteristics (Fellström \& Gunnarsson, 1995). Of these, 56 swine isolates matched the criteria for $B$. pilosicoli. In this study, only nine of the 19 human isolates fully matched the characteristics in the biochemical characterization criteria proposed for group IV, now known as $B$. pilosicoli (Fellström \& Gunnarson, 1995). On the other hand, none of the isolates studied here matched any of the other groups proposed in this classification and were still most closely matched to $B$. pilosicoli. This discrepancy may be because the criteria were established using only swine isolates from one geographic area (Sweden), or because human spirochaete isolates represent a more heterogeneous population of $B$. pilosicoli.

Similarly, DNA sequencing of a variable region of the 16S rRNA gene revealed that human intestinal spirochaetes showed variation, but were still most closely related to each other and to $B$. pilosicoli. Seven swine isolates of $B$. pilosicoli did not show any variation in this region, although they had polymorphisms in other regions of the 16S rDNA sequence (Petterson et al., 1996).

Further analysis of some of these isolates using PCR and Western blotting with a monoclonal antibody, both reported to be specific for $B$. pilosicoli, showed that 16 isolates out of 16 were positive by PCR and nine out of nine were positive by Western blotting (C. Bakatselou \& S. P. Barrett, unpublished results; Rayment et al., 1997). It is postulated that the considerable variation in the biochemical data and the variation of up to $3 \mathrm{bp}$ in the $283 \mathrm{bp}$ analysed, is simply intra-species variation. For comparison, there were up to $2 \mathrm{bp}$ differences amongst isolates of B. hyody- senteriae and up to 4 bp differences between different $B$. innocens isolates in the same region (Table 2; Fellström et al., 1995; Petterson et al., 1996). In an unrelated genus, no differences have been found in the same region for the pathogen Mycobacterium tuberculosis, but up to $3 \mathrm{bp}$ differences were found for several other mycobacterial species causing opportunist infections (Kirschner et al., 1993). However, it has to be borne in mind that this difference matrix is based on the comparison of only a relatively short sequence $(283 \mathrm{bp})$ with very few informative nucleotides. The data in Table 2 highlight the limitation of this: the region analysed also showed only $2 \mathrm{bp}$ differences between the published sequences of the type strains of $B$. hyodysenteriae and B. innocens (Table 2). Analysis of the almost complete published sequence of the $16 \mathrm{~S}$ rRNA gene shows a different relationship, where different isolates of the same species group together, separated from other species (Petterson et al., 1996). Based on all the current data, the most likely conclusion is that all 19 isolates belong to the same species, B. pilosicoli, although it cannot be excluded that some of them are other uncharacterized Brachyspira/Serpulina species. In any case, it has been clearly shown that the human isolates in this study form a distinct branch, including $B$. pilosicoli, represented by $\mathrm{P} 43 / 6 / 78^{\mathrm{T}}$, that differs from other described species of Brachyspira/Serpulina or B. aalborgi.

Isolates were selected to represent different geographical origins. There was no correlation between geographical origin and the phenotypic variation or the sequence type of the isolates. IS-A and IS-B were found among isolates from all countries. The single isolates with sequence IS-B and IS-C were both from Omani patients. This may simply be because more isolates from Oman than from any other country were included in this study, or it may be that the high prevalence of intestinal spirochaetosis in Oman reflects the presence of multiple genetic types (Barrett, 1990).

It has previously been noted that $B$. pilosicoli contains a unique 'signature' sequence of 5' AGTTTTTTCGCTTCA $3^{\prime}$ in their 16S rDNA (173-189 bp; Fig. 1), which is a key factor in identifying $B$. pilosicoli and has been used to design a primer for PCR-based detection of this organism (Park et al., 1995). However, it was found that the single IS-C isolate differed in this region in having only five rather than six ' $\mathrm{T}$ ' nucleotides. As this difference is in the centre of the primer used which otherwise differs by $7-8 \mathrm{bp}$ from other Serpulina species, this may have only minor consequences for the specificity of this assay. In fact, this isolate has produced a positive result in a species-specific PCR (C. Bakatselou \& S. P. Barrett, unpublished results).

Based on biochemical and DNA sequencing analyses, it is concluded that all human intestinal spirochaetes belong to the species $B$. pilosicoli. It is of interest to note that none of the other Brachyspira/Serpulina species were found. This is in contrast with swine faecal isolates, which represent at least five different 
species of Serpulina. This may suggest that B. pilosicoli has a different host-pathogen interaction allowing it to colonize a broader host range than other Serpulina species.

The clinical significance of $B$. pilosicoli in human infection remains unclear and needs further study. $B$. pilosicoli has been demonstrated to cause spirochaetosis in pigs (Trott et al., 1996b; Muniappa et al., 1997; Thomson et al., 1997), and there was a significant correlation between the presence of group IV spirochaetes (now known to be B. pilosicoli) and occurrence of diarrhoea in pigs (Fellström \& Gunnarson, 1995). Most human intestinal spirochaetes are obtained from humans with diarrhoea (Lee \& Hampson, 1994). Also, most, but not all, of the intestinal isolates studied here were obtained from patients with intestinal problems. However, this does not prove an aetiological link. It could be that colonization by other agents causing intestinal problems may 'flush out' spirochaetes that are normally residing in a healthy intestine. It may also be the case that only certain strains of $B$. pilosicoli are pathogenic, depending on their ability to produce specific toxins or other virulence factors. This is, for example, observed with Escherichia coli, where different strains can either produce enterotoxins or cytotoxins or penetrate epithelial cells.

In summary, it is concluded, based on phenotypic analysis and DNA sequencing, that there is considerable variation amongst human intestinal spirochaetes, but that they all belong to or are closely related to the species $B$. pilosicoli. The clinical significance of human $B$. pilosicoli infection remains unclear.

\section{ACKNOWLEDGEMENTS}

We wish to thank G. Dettori, I. Saint Girons, D. Hampson and J. Holton for supplying the Italian, French, Australian and UK isolates.

\section{REFERENCES}

Atyeo, R. F., Oxberry, S. L. \& Hampson, D. J. (1996). Pulsed-field gel electrophoresis for sub-specific differentiation of Serpulina pilosicoli (formerly 'Anguillina coli'). FEMS Microbiol Lett 141, $77-81$.

Barrett, S. P. (1990). Intestinal spirochaetosis in a Gulf Arab population. Epidemiol Infect 104, 261-266.

Barrett, S. P., Holton, J. J. M., Hookey, J. V., Costas, M., Ganner, M., Mundy, R. \& Wright, D. J. M. (1996). Heterogeneity of human intestinal spirochaetes demonstrated by one-dimensional polyacrylamide gel electrophoresis of proteins visualised by ${ }^{35} \mathrm{~S}-$ methionine labelling and coomassie blue staining. $J$ Med Microbiol 45, 6-9.

De Smet, K. A. L., Brown, I. N., Yates, M. \& Ivanyi, J. (1995). Ribosomal internal transcribed spacer sequences are identical among Mycobacterium avium-intracellulare complex isolates from AIDS patients, but vary among isolates from elderly pulmonary disease patients. Microbiology 141, 2739-2747.

Fellström, C. \& Gunnarson, A. (1995). Phenotypical charac- terisation of intestinal spirochaetes isolated from pigs. Res $V e t$ Sci 59, 1-4.

Fellström, C., Petterson, B., Uhlén, M., Gunnarson, A. \& Johansson, K.-E. (1995). Phylogeny of Serpulina based on sequence analysis of the 16S rRNA gene and comparison with a scheme involving biochemical classification. Res Vet Sci 59, 5-9.

Hovind-Hougen, K., Birch-Andersen, A., Henrik-Nielsen, R., Orholm, M., Pedersen, J. O., Teglbjaerg, P. S. \& Thaysen, E. H. (1982). Intestinal spirochetosis: morphological characterization and cultivation of the spirochete Brachyspira aalborgi gen. nov., sp. nov. J Clin Microbiol 16, 1127-1136.

Kirschner, P., Springer, B., Vogel, U., Meier, A., Wrede, A., Kiekenbeck, M., Bange, F.-C. \& Böttger, E. C. (1993). Genotypic identification of mycobacteria by nucleic acid sequence determination: report of a 2-year experience in a clinical laboratory. J Clin Microbiol 31, 2882-2889.

Lee, J. I. \& Hampson, D. J. (1992). Intestinal spirochaetosis colonizing Aborigines from communities in the remote north of Western Australia. Epidemiol Infect 109, 133-141.

Lee, J. I. \& Hampson, D. J. (1994). Genetic characterisation of intestinal spirochaetes and their association with disease. $J \mathrm{Med}$ Microbiol 40, 365-371.

Muniappa, N., Mathiesen, M. R. \& Duhamel, G. E. (1997). Laboratory identification and enteropathogenicity testing of Serpulina pilosicoli associated with porcine colonic spirochetosis. J Vet Diagn Invest 9, 165-171.

Park, N. Y., Chung, C. Y., McLaren, A. J., Atyeo, R. F. \& Hampson, D. J. (1995). Polymerase chain reaction for identification of human and porcine spirochaetes recovered from cases of spirochaetosis. FEMS Microbiol Lett 125, 225-230.

Petterson, B., Fellström, C., Anderson, A., Uhlén, M., Gunnarsson, A. \& Johansson, K.-E. (1996). The phylogeny of intestinal porcine spirochactes (Serpulina species) based on sequence analysis of the 16S rRNA gene. J Bacteriol 178, 4189-4199.

Rayment, S. J., Barrett, S. P. \& Livesley, M. A. (1997). Sub-specific differentiation of intestinal spirochaete isolates by macrorestriction fragment profiling. Microbiology 143, 2923--2929.

Sanna, A., Dettori, G., Grillo, R., Rossi, A. \& Chiarenza, D. (1982). Isolation and propagation of a strain of treponema from the human digestive tract - preliminary report. $\operatorname{Ig} \operatorname{Mod} 77,287-297$.

Stanton, T. B., Trott, D. J., Lee, J. I., McLaren, A. J., Hampson, D. J., Paster, B. J. \& Jensen, N. S. (1996). Differentiation of intestinal spirochaetes by multilocus enzyme electrophoresis analysis and 16S rRNA sequence comparisons. FEMS Microbiol Lett 136, 181-186.

Stanton, T. B., Fournié-Amazouz, E., Postic, D., Trott, D. J., Grimont, P. A., Baranton, G., Hampson, D. J. \& Saint Girons, I. (1997). Recognition of two new species of intestinal spirochetes: Serpulina intermedia sp. nov. and Serpulina murdochii sp. nov. Int J Syst Bacteriol 47, 1007-1012.

Taylor, D. J. \& Alexander, T. J. L. (1971). The production of dysentery in swine by feeding cultures containing a spirochaete. Br Vet $J 127,58-61$.

Thomson, J. R., Smith, W. J., Murray, B. P. \& McOrist, S. (1997). Pathogenicity of three strains of Serpulina pilosicoli in pigs with a naturally acquired intestinal flora. Infect Immun $\mathbf{6 5}$, 3693-3700.

Trott, D. J., Stanton, T. B., Jensen, N. S., Duhamel, G. E., Johnson, J. L. \& Hampson, D. J. (1996a). Serpulina pilosicoli sp. nov., the agent of porcine intestinal spirchetosis. Int J Syst Bacteriol 46, 206-215.

Trott, D. J., Huxtable, C. R. \& Hampson, D. J. (1996b). Experi- 
mental infection of newly weaned pigs with human and porcine strains of Serpulina pilosicoli. Infect Immun 64, 4648-4654.

Trott, D. J., Stanton, T. B., Jensen, N. S. \& Hampson, D. J. (1996c). Phenotypic characteristics of Serpulina pilosicoli the agent of intestinal spirochaetosis. FEMS Microbiol Lett 142, 209-214.

Trott, D. J., Jensen, N. S., Saint Girons, I., Oxberry, S. L., Stanton,
T. B., Lindquist, D. \& Hampson, D. J. (1997). Identification and characterization of Serpulina pilosicoli isolates recovered from the blood of critically ill patients. J Clin Microbiol 35, 482-485.

Validation List No. 64 (1998). Validation of publication of new names and new combinations previously effectively published outside the IJSB. Int $J$ Syst Bacteriol 48, 327-328. 
